\title{
LA CONCORDANCIA DEL VERBO CON EL OBJETO COMO FENÓMENO COMPLEJO*
}

\author{
KATEŘINA ZIKOVÁ \\ Universidad Carolina, Praga
}

\section{THE VERB-OBJECT AGREEMENT AS A COMPLEX PHENOMENON}

In this work, the pronominal reduplication in Spanish is interpreted as an agreement of the verb with the object by means of a clitic. In this way, the object resembles the subject, which agrees with the verb by means of an affix, hence the suggestion of the attributes implicit and explicit for the object. However, while the subject-verb agreement is absolutely regular, the agreement of the object is conditioned by diverse factors. These factors are the main object of investigation in this work. Finally, we present the concept of accessibility and suggest that it unites all the factors of the object-verb agreement under one main principle.

Keywords: pronominal reduplication; agreement; implicit object; explicit object; accessibility

Palabras clave: reduplicación pronominal; concordancia; objeto implícito; objeto explícito; accesibilidad

\section{Introducción}

Este estudio analiza los factores que influyen en la forma del objeto directo e indirecto. Distinguimos tres formas básicas del objeto:

1. clítico,

2. forma léxica reduplicada,

3. forma léxica no reduplicada.

Seguimos el concepto de la reduplicación como concordancia del predicado con el objeto mediante el clítico (García-Miguel 1991). A diferencia de la interpretación tradicional de la reduplicación del objeto pospuesto como redundancia (es decir, anomalía), ésta ofrece una posibilidad de incorporar el fenómeno en el sistema. En un análisis funcional, el clítico, como marca de concordancia, forma parte del predicado. Partien-

Este artículo forma parte del proyecto "Program rozvoje vědních oblastí na Univerzitě Karlově č. P10", subprograma "Románské jazyky ve světle jazykových korpusư”. 
do de esta teoría, definimos las dos primeras formas como las que concuerdan con el predicado - la primera significa un objeto implícito (analógicamente a sujeto implícito); la segunda, un objeto explícito.

Tradicionalmente, se distingue la reduplicación del objeto pospuesto y la del objeto antepuesto. La anteposición del objeto implica tematización, es una posición marcada y así la reduplicación se considera obligatoria. Por otro lado, la reduplicación del objeto pospuesto es a menudo considerada redundante. En este trabajo intento alcanzar una visión compleja del fenómeno, mostrando, por ejemplo, que ni la reduplicación del objeto tematizado es regular, ni la del objeto pospuesto es redundante. Hay muchos factores que influyen en la forma del objeto y hay que tomarlos todos en cuenta.

Otro concepto define tres actantes centrales - sujeto, objeto indirecto y objeto directo-, establece su jerarquía y propone la concordancia con el predicado como su propiedad específica (García-Miguel y Vázquez Rozas 1994; Vázquez Rozas 1995). La centralidad es una categoría gradual: el actante más central tiende más a concordar con el predicado. Este principio funciona también dentro de los dos tipos de objeto. Generalmente, el sujeto es el actante más central, seguido por el OI, y en el tercer lugar está el OD.

Para el análisis he utilizado la base de datos sintácticos ADESSE de la Universidad de Vigo. Es la versión ampliada de la BDS de la Universidad de Santiago de Compostela. Contiene la parte del español actual del corpus Arthus, constituida por casi un millón y medio de palabras. El 80\% de los textos son de España y el 20\% de América. El 19\% de los textos pertenecen a la lengua hablada, sin embargo, en mis estadísticas he utilizado solamente la parte escrita en su totalidad (excepto en las que se dedican precisamente al habla). La base de datos contiene anotación sintáctica y semántica de los verbos y de sus actantes. Permite distinguir distintos tipos de procesos, basados en la clase semántica del verbo. A cada tipo de proceso le corresponde un esquema sintáctico-semántico que determina el número y tipo de actantes exigidos por el verbo. Además, la base de datos distingue las características formales de los actantes, así que permite buscar las relaciones entre las formas del objeto y el tipo del verbo.

\section{Formas del objeto}

El sujeto, el objeto directo y el indirecto son los actantes más exigidos por el verbo - los actantes centrales (García-Miguel y Vázquez Rozas 1994; Vázquez Rozas 1995). Dado que suelen formar parte de la valencia del verbo, se han gramaticalizado en varios aspectos. Un rasgo fundamental de esta gramaticalización es la concordancia. Mientras que el predicado concuerda con el sujeto mediante un afijo morfológico, con el objeto puede concordar de una manera más bien sintáctica, es decir, mediante un clítico pronominal (García-Miguel 1991). Se trata de la llamada reduplicación. A su vez, el clítico, como marca de concordancia, permite omitir el objeto léxico explícito; hablamos entonces de objeto implícito. Sin embargo, mientras que la concordancia con el sujeto es totalmente regular, el objeto puede aparecer también en la forma léxica no reduplicada por el clítico, lo cual sucede en la mayoría de los casos con el objeto directo. Así que las tres formas básicas del objeto tendrán en este trabajo las siguientes denominaciones: 
1. Objeto implícito (solo clítico):

Me gusta la música. La quiero.

2. Objeto explícito concordado (objeto léxico doblado por clítico):

Le duele la cabeza a Juanita. A mí no me invitaron.

3. Objeto explícito no concordado (solo objeto léxico):

Dieron un premio a Paco. Dos hijos tengo, no tres.

La distribución de estas tres formas del objeto indirecto y directo es la siguiente:

Tabla 1

\begin{tabular}{|l|c|c|c|c|}
\hline & OI & $\%$ & OD & $\%$ \\
\hline objeto implícito & 9.393 & $75 \%$ & 14.061 & $19,7 \%$ \\
\hline objeto explícito concordado & 1.532 & $12,2 \%$ & 908 & $1,3 \%$ \\
\hline objeto explícito no concordado & 1.593 & $12,7 \%$ & 56.349 & $79 \%$ \\
\hline
\end{tabular}

Las formas explícitas concordadas del objeto (el llamado objeto reduplicado o doblado) representan una minoría entre las formas del objeto en general. Sin embargo, se nota una gran diferencia entre el objeto directo y el indirecto. La reduplicación del OD es más bien excepcional, mientras que la reduplicación del OI sigue aumentando (Vázquez Rozas y García Salido 2012). En la Tabla 1 se ve muy claramente que el objeto que suele ser implícito (OI) tiende más a la concordancia que el que suele aparecer explícito (OD).

Para una imagen más clara de la diferencia cuantitativa entre el objeto explícito concordado y el no concordado, véase la Tabla 2. Podemos ver que el verbo concuerda con la mitad de los objetos indirectos explícitos. En el caso del objeto directo, el número no irrelevante de los OD concordados parece diminuto en contraste con el número de los OD no concordados.

Tabla 2

\begin{tabular}{|l|c|c|c|c|}
\hline & OI & $\%$ & OD & $\%$ \\
\hline objeto explícito concordado & 1.532 & $49 \%$ & 908 & $1,6 \%$ \\
\hline objeto explícito no concordado & 1.593 & $51 \%$ & 56.349 & $98,4 \%$ \\
\hline
\end{tabular}

\section{Factores que influyen en la forma del objeto}

En ADESSE he investigado la influencia de los distintos factores en la forma del objeto. Me he inspirado en la lista de factores creada por Barrenechea y Orecchia (1979) para su investigación de la reduplicación del objeto en el español de Buenos Aires (sin embargo, hay varias diferencias frente a la lista original):

1. Carácter del objeto

a. Tipo de objeto: directo / indirecto

b. "Clase de palabras" y persona: pronombre (1a / 2a / 3a p.) / sustantivo / oración

c. Preposición $a$, animacidad: con / sin preposición; animado / inanimado

d. Determinación: determinado / indeterminado / no determinado 


\section{Carácter del verbo}

e. Valencia sintáctica: monovalente / bivalente / trivalente

f. Valencia semántica: paciente / receptor / beneficiario / experimentador etc.

\section{Carácter del enunciado}

g. Estructura comunicativa (temática): tema / rema

h. Estructura informativa (topicalidad): tópico / foco

\section{Registro}

i. Canal: oral / escrito

j. Registro social y regional: formal / coloquial; variantes españolas / americanas

A primera vista, los tres parámetros que más determinan la concordancia del verbo con el objeto son el tipo de objeto, la "clase de palabras" a la que éste pertenezca y la estructura comunicativa, la cual determina la posición del objeto. Entonces, podemos formular cinco afirmaciones preliminares:

1. La concordancia del verbo con los pronombres personales es casi regular:

Nos interesa a nosotras también. Lo eligieron a él.

2. La concordancia con los objetos indirectos antepuestos es casi regular:

A Lucía le gusta el cine. A los chicos les dieron mucho dinero.

3. El verbo concuerda con menos de la mitad de los objetos directos antepuestos:

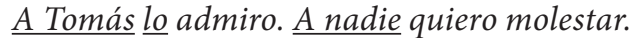

4. El verbo concuerda con más de un tercio de los objetos indirectos pospuestos:

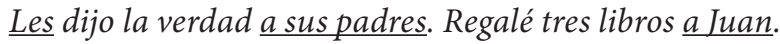

5. La concordancia con los objetos directos pospuestos es relativamente excepcional:

Tengo tres amigos muy buenos. Quiero un café, por favor.

Tabla 3

\begin{tabular}{|l|c|c|c|c|}
\hline & + concordancia & $\%$ & - concordancia & $\%$ \\
\hline pronombres personales & 563 & $95 \%$ & 27 & $5 \%$ \\
\hline OI antepuestos & 315 & $93 \%$ & 24 & $7 \%$ \\
\hline OD antepuestos & 415 & $42 \%$ & 564 & $58 \%$ \\
\hline OI pospuestos & 808 & $36 \%$ & 1.453 & $64 \%$ \\
\hline OD pospuestos & 263 & $1 \%$ & 50.282 & $99 \%$ \\
\hline
\end{tabular}

Sin embargo, la realidad es mucho más compleja. Los distintos factores se entrecruzan y condicionan entre sí. En general podemos afirmar que el objeto que tenga más de las propiedades características del sujeto (véase en el apartado siguiente), tenderá más a concordar. Otro aspecto importante que influye en la concordancia del verbo con el objeto es el registro concreto de la lengua, es decir, hay que distinguir entre lengua escrita y oral, formal e informal, y asimismo entre las distintas variantes del español. En los apartados siguientes trataremos brevemente cada uno de los factores relevantes. 


\subsection{Tipo de objeto}

Algunos factores de los que depende la forma del objeto son los mismos que establecen la jerarquía de los actantes centrales. García-Miguel y Vázquez Rozas (1994) unen estos factores bajo los términos de topicalidad y agentividad (capacidad de actuar). El sujeto es el actante más central, presente en casi todo enunciado, lo que es causa de su gramaticalización dentro de la estructura de la oración. El rasgo más importante de esta gramaticalización es la concordancia regular con el predicado, la que permite al sujeto aparecer en forma implícita (es decir, semántica y fonéticamente mínima). Suele desempeñar el papel semántico de agente, así que es típicamente animado y determinado. Si es explícito, suele ocupar la posición temática (preverbal), la cual corresponde al tópico del enunciado (Jiménez Juliá 1996).

Por el contrario, el objeto directo es típicamente inanimado, que es la característica principal del paciente. Desde la perspectiva informativa le corresponde la función del foco, así que su posición no marcada es la remática (postverbal) y suele tener forma explícita no concordada. Si es tematizado, normalmente pasa a ser tópico, así que sube en la escala de la topicalidad y tiende más a concordar.

El objeto indirecto desempeña dos papeles principales. Como experimentador ( $\underline{\text { Le }}$ gustan las películas checas.) se acerca bastante al sujeto - es normalmente animado, determinado e implícito, y si es explícito, está en la posición temática, característica del tópico. Su concordancia es casi regular. Como receptor (Le han regalado un teléfono a José.) se acerca más al paciente (la entidad que sufre la acción), suele ser explícito y focal (posición postverbal), pero es también animado y tiende a concordar con el verbo.

En las tablas 4-7 podemos ver la distribución de la posición, animacidad, clase de palabras y concordancia de los tres actantes centrales. En cuanto a la posición, el sujeto ocupa la posición preverbal con mucha más frecuencia (68\%) que el objeto y la diferencia entre el OI (20\%) y el OD (2\%) es también muy relevante. Es notable que el objeto indirecto suele ser animado e implícito incluso con mayor frecuencia que el sujeto. El objeto directo es el que aparece con mayor frecuencia en forma de sustantivo (65\%). Y por último, podemos ver que con el OI, la concordancia (la presencia del clítico en general) alcanza $87 \%$ y con el OD, solamente $21 \%$.

Tabla 4

\begin{tabular}{|l|c|c|c|c|c|c|}
\hline & SUJ & $\%$ & OI & $\%$ & OD & $\%$ \\
\hline antepuesto & 30.985 & $68,4 \%$ & 588 & $19,7 \%$ & 1.054 & $2 \%$ \\
\hline pospuesto & 14.341 & $31,6 \%$ & 2.392 & $80,3 \%$ & 50.682 & $98 \%$ \\
\hline
\end{tabular}

Tabla 5

\begin{tabular}{|l|c|c|c|c|c|c|}
\hline & SUJ & $\%$ & OI & $\%$ & OD & $\%$ \\
\hline animado & 98.298 & $74,5 \%$ & 11.563 & $92,4 \%$ & 13.315 & $18 \%$ \\
\hline inanimado & 33.691 & $25,5 \%$ & 955 & $7,6 \%$ & 58.002 & $82 \%$ \\
\hline
\end{tabular}


Tabla 6

\begin{tabular}{|l|c|c|c|c|c|c|}
\hline & \multicolumn{1}{|c|}{ SUJ } & $\%$ & OI & $\%$ & OD & $\%$ \\
\hline implícito & 76.837 & $58,2 \%$ & 9.393 & $75 \%$ & 14.061 & $19,7 \%$ \\
\hline pron. personal & 5.563 & $4,2 \%$ & 366 & $2,9 \%$ & 210 & $0,3 \%$ \\
\hline sustantivo & 47.270 & $35,8 \%$ & 2.756 & $22 \%$ & 46.539 & $65,3 \%$ \\
\hline oración & 2.304 & $1,7 \%$ & 2 & $0 \%$ & 10.448 & $14,7 \%$ \\
\hline otro & 4 & $0 \%$ & 0 & $0 \%$ & 23 & $0 \%$ \\
\hline
\end{tabular}

Tabla 7

\begin{tabular}{|l|r|r|r|c|c|c|}
\hline & \multicolumn{1}{|c|}{ SUJ } & $\%$ & OI & $\%$ & OD & $\%$ \\
\hline + concordancia & 129.289 & $100 \%$ & 10.925 & $87,3 \%$ & 14.967 & $21 \%$ \\
\hline - concordancia & 0 & $0 \%$ & 1.593 & $12,7 \%$ & 5.6351 & $79 \%$ \\
\hline
\end{tabular}

\subsection{Clase de palabras}

Según la tradición checa (Zavadil y Čermák 2010), la forma del objeto, en general, es el sustantivo sintáctico. Este término abarca tanto las llamadas frases nominales o preposicionales como otras formas morfológica o sintácticamente sustantivadas. Es decir, son todas formas capaces de ocupar en una oración la misma posición que un sustantivo. Es un paradigma de formas que pueden desempeñar la función de sujeto u objeto. La mayoría la forman los pronombres personales, los sustantivos y las oraciones sustantivas:

Tabla 8

\begin{tabular}{|l|r|r|r|r|r|r|r|c|}
\hline & \multicolumn{4}{|c|}{ OI } & \multicolumn{4}{c|}{ OD } \\
\cline { 2 - 9 } & + con. & $\%$ & - con. & $\%$ & + con. & $\%$ & - con. & $\%$ \\
\hline pron. personal & 340 & $92,9 \%$ & 26 & $7,1 \%$ & 209 & $99,5 \%$ & 1 & $0,5 \%$ \\
\hline sustantivo & 1.191 & $43,2 \%$ & 1.565 & $56,8 \%$ & 687 & $1,5 \%$ & 45.852 & $98,5 \%$ \\
\hline oración & 0 & $\varnothing$ & 2 & $\varnothing$ & 11 & $0,1 \%$ & 10.437 & $99,9 \%$ \\
\hline
\end{tabular}

La Tabla 8 muestra que los objetos pronominales concuerdan prácticamente siempre con el predicado. De los 26 casos del OI pronominal no concordado, la mayoría pertenecen a los verbos reflexivos (La abuela dice que me parezco a él). De los OI en forma de sustantivo, la concordancia no alcanza la mitad, y entre los OD en forma de sustantivo u oración, la concordancia es relativamente mínima.

Los pronombres personales son inherentemente animados y determinados. Tienen carácter topical: los de la primera y segunda persona refieren a los participantes del acto comunicativo (deixis), los de la tercera suelen referirse a personas mencionadas ya en el discurso (anáfora). Es decir, no aportan información nueva. Estas propiedades corresponden al hecho de que los pronombres personales en función de objeto normalmente aparecen en forma implícita de clítico (no me gusta), y esta marca de concordancia per- 
manece obligatoria cuando hay que expresarlos explícitamente, con la forma tónica. Ésta siempre va acompañada de la preposición $a$ y es la forma marcada del objeto pronominal, con un valor focalizador o contrastivo (a mí no me gusta).

En cuanto a los objetos que tienen forma de sustantivo, la concordancia depende tanto del tipo de objeto como de sus rasgos semánticos y formales. Los nombres propios se parecen mucho a los pronombres personales. Tienen carácter inherentemente animado y determinado, y llevan la preposición $a$. Sin embargo, la concordancia con todos los sustantivos, incluso con los nombres propios, depende en primer lugar de su función informativa (tópico vs. foco). Solo después depende de su animacidad, determinación o la presencia de la preposición $a$.

Las oraciones sustantivas en función objeto normalmente no se reduplican con un clítico, dado su carácter sumamente periférico, focal e inanimado, así como semántica y fonéticamente muy cargado. Así por ejemplo los verbos de comunicación que exigen una oración en posición del $\mathrm{OD}$, como el verbo decir, tienen una frecuencia de concordancia con el OD muy baja. Entre los pocos ejemplos encontrados de oraciones concordadas, destacan las precedidas por el marcador ya, que expresa una cierta énfasis (Ya te lo dije que volvería.).

\subsection{Preposición a y animacidad}

Tradicionalmente, la preposición $a$ ha sido tratada como marca de función del objeto indirecto y como marca de animacidad del objeto directo. Las distintas interpretaciones de la preposición a delante de ambos tipos de objeto han sido resumidas por Ariza (2013). Después de presentar brevemente las distintas teorías, el autor extrae varios puntos unificadores que presenta como conclusión. Resulta que la preposición a es marca de determinación, en primer lugar, y de animacidad o persona, en segundo lugar. Como el objeto indirecto es casi siempre animado y/o determinado, la preposición $a$ delante de este objeto está totalmente gramaticalizada. Al contrario, el objeto directo lleva la preposición solamente en los casos marcados, fuera del ámbito prototípico de paciente, es decir, en los casos animados que se asemejan más al OI. Esta tendencia es equivalente a la de la presencia del clítico, es decir, la concordancia.

Sobre la base de estas afirmaciones podríamos creer en la validez de la teoría generativista llamada generalización de Kayne (Fernández Soriano 1993), según la cual la presencia de la preposición a determina la concordancia. Sin embargo, mostraremos que la presencia de esta preposición es solo uno de los factores que condicionan la concordancia del objeto directo (véase Tabla 9). Ni siquiera en el dialecto rioplatense, que había sido tomado como muestra de la validez de esta teoría, se encuentra la concordancia "en estricta distribución complementaria con los objetos directos no precedidos por la marca $a$ ” (Fernández Soriano 1993).

Tabla 9

\begin{tabular}{|l|c|c|c|c|}
\hline & + concordancia & $\%$ & - concordancia & $\%$ \\
\hline + preposición & 425 & $10,6 \%$ & 3.578 & $89,4 \%$ \\
\hline - preposición & 462 & $1 \%$ & 47.069 & $99 \%$ \\
\hline
\end{tabular}


Se ve que el número de casos concordados con preposición (lo miro a Sandro como si fuera un salvavidas) es comparable a los sin preposición (de repente Jano lo comprendió todo). Sin embargo, la mayoría de los OD concordados sin preposición que están en la posición postverbal, son los casos del pronombre todo. De todas formas, la presencia de la preposición $a$ tiene repercusión relevante en la concordancia del OD (10\% frente al 1\%).

Algunos verbos rigen la presencia o ausencia de la preposición $a$, sin tomar en cuenta las propiedades del objeto. Entre los verbos que rechazan la preposición $a$ incluso con los OD animados o determinados, destacan tener y haber.

La influencia de la categoría de animacidad en la concordancia del verbo con el objeto es comparable a la de la preposición $a$. Vázquez Rozas (1995) habla de una "tendencia general de las lenguas a favorecer la concordancia del verbo con los argumentos altamente animados”. Es natural que los seres vivos tiendan a participar de cualquier manera en la acción expresada por el verbo, mientras que los objetos inanimados suelen ser pasivos y quedar afectados por la acción. Veamos la relación de la animacidad con la concordancia en la Tabla 10:

Tabla 10

\begin{tabular}{|l|c|c|c|c|c|c|c|c|}
\hline \multirow{2}{*}{} & \multicolumn{4}{|c|}{ OI } & \multicolumn{4}{c|}{ OD } \\
\cline { 2 - 9 } & + con. & $\%$ & - con. & $\%$ & + con. & $\%$ & - con. & $\%$ \\
\hline animado & 1.369 & $57,1 \%$ & 1.027 & $42,9 \%$ & 420 & $8,7 \%$ & 4.428 & $91,3 \%$ \\
\hline inanimado & 163 & $22,4 \%$ & 566 & $77,6 \%$ & 488 & $0,9 \%$ & 51.921 & $99,1 \%$ \\
\hline
\end{tabular}

Vemos que más de la mitad de los OI animados concuerdan con el verbo, mientras que con los OI inanimados son solo $22 \%$. En cuanto al OD, la animacidad influye un poco menos en la concordancia con el verbo que la presencia de la preposición $a$.

La lengua tiene carácter antropocéntrico (Vázquez Rozas 1995). En primer lugar, los humanos hablan sobre ellos mismos, luego sobre los demás, luego sobre los animales y cosas concretas, y en último lugar, sobre entidades abstractas. El tópico del enunciado, que tiende a concordar con el verbo, es más típicamente el hablante u otra persona concreta, mientras que el foco, que no suele concordar, es típicamente una cosa o una proposición.

\subsection{Determinación}

La determinación es la última de las características del objeto que influye de una manera notable en su concordancia con el verbo. A esta categoría gramatical le corresponden distintos valores semántico-pragmáticos:

1. El valor básico es que el hablante supone que el interlocutor es capaz de reconocer la entidad determinada - como mencionada en el contexto previo o como conocida personal o universalmente:

Conozco bien a los hijos de María.

2. En español, el artículo definido puede tener valor de pronombre posesivo, sobre todo con las partes del cuerpo:

Me duele la cabeza. 
3. También puede señalar la singularidad de la entidad determinada:

Se me perdió el gato más negro.

4. Por último, puede referirse a todos los miembros de un grupo:

Los médicos entraron en huelga.

En general, el equivalente semántico-pragmático de la categoría de determinación podría ser la identificabilidad. Sin embargo, la relación entre las categorías formales y sus valores no suele ser unívoca. Así, por ejemplo, no podemos considerar como identificable una entidad determinada seguida de oración relativa en subjuntivo (Mataré al loco que intente seducir a mi mujer).

La determinación puede señalarse con un determinante, o puede ser inherente, como en el caso de los pronombres personales y los nombres propios. Vázquez Rozas (1995) divide los objetos según este criterio en determinados, indeterminados y no determinados:

1. Entre los objetos determinados figuran los pronombres personales, los demostrativos, posesivos, interrogativos y relativos, los nombres propios y los sustantivos con un artículo o con un determinante demostrativo o posesivo.

2. Como objetos indeterminados señalamos los pronombres indefinidos y los sustantivos con un determinante indefinido.

3. El conjunto de los objetos no determinados abarca los sustantivos sin ningún determinante.

La Tabla 11 contiene datos de García-Miguel y Vázquez Rozas (1994), ya que la ADESSE no permite la búsqueda según el criterio de la determinación:

Tabla 11

\begin{tabular}{|l|r|r|r|r|r|c|c|c|}
\hline & \multicolumn{4}{|c|}{ OI } & \multicolumn{4}{c|}{ OD } \\
\cline { 2 - 9 } & + con. & $\%$ & - con. & $\%$ & + con. & $\%$ & - con. & $\%$ \\
\hline determinado & 1.876 & $64,6 \%$ & 1.030 & $35,4 \%$ & 960 & $4,1 \%$ & 22.541 & $95,9 \%$ \\
\hline indeterminado & 153 & $54,4 \%$ & 128 & $45,6 \%$ & 106 & $1 \%$ & 10.068 & $99 \%$ \\
\hline no determinado & 3 & $13,6 \%$ & 19 & $86,4 \%$ & 10 & $0,2 \%$ & 6.199 & $99,8 \%$ \\
\hline
\end{tabular}

Podemos ver que los objetos no determinados prácticamente no concuerdan. De todas formas, este factor tiene mucha importancia en la concordancia del verbo con el objeto. Como veremos, la determinación tiene mucho en común con la topicalidad, tratada en este artículo bajo el concepto de la estructura informativa.

\subsection{Valencia sintáctica y semántica}

Veamos ahora la influencia del mismo verbo en su concordancia con el objeto. La valencia sintáctica determina qué actantes exigirá el verbo (SUJ, OI, OD), mientras que la valencia semántica determina el papel semántico de cada actante (agente, receptor, paciente). Como las dos categorías son inseparables, las agrupamos en un solo apartado. 
Los apartados anteriores se han ocupado de las características del objeto explícito. Ahora vamos a incluir también la forma implícita, para crear una imagen más íntegra del fenómeno. La Tabla 12 representa la relación entre la valencia sintáctica y la forma del objeto indirecto. Es decir, la distribución de las formas del objeto en relación con la presencia o ausencia de los demás actantes centrales, sujeto y objeto directo:

1. OI monovalente (solo OI): $i$ Me basta!

2. OI bivalente (SUJ + OI): Le duele la cabeza.

3. OI trivalente (SUJ + OI + OD): Le han dado un golpe.

Tabla 12

\begin{tabular}{|l|c|c|c|c|c|c|}
\hline & implícito & $\%$ & + concord. & $\%$ & - concord. & $\%$ \\
\hline OI 1valente & 5 & $100 \%$ & 0 & $0 \%$ & 0 & $0 \%$ \\
\hline OI 2valente & 2.547 & $73,6 \%$ & 602 & $17,4 \%$ & 313 & $9 \%$ \\
\hline OI 3valente & 5.119 & $72,8 \%$ & 749 & $10,7 \%$ & 1.160 & $16,5 \%$ \\
\hline
\end{tabular}

El objeto indirecto monovalente (Tabla 13) es muy raro y solo aparece en forma implícita. Salvo un uso raro del verbo amanecer, los ejemplos pertenecen al verbo existencial bastar. Se trata de enunciaciones cortas del tipo me basta en el sentido de "estoy harto".

Tabla 13

\begin{tabular}{|l|c|c|c|c|c|c|}
\hline & implícito & $\%$ & + concord. & $\%$ & - concord. & $\%$ \\
\hline bastar & 4 & $100 \%$ & 0 & $0 \%$ & 0 & $0 \%$ \\
\hline amanecer & 1 & $100 \%$ & 0 & $0 \%$ & 0 & $0 \%$ \\
\hline
\end{tabular}

En las construcciones bivalentes (Tabla 141), lo más típico es que un objeto indirecto implícito se una con un sujeto pospuesto. Se trata sobre todo de los verbos de sensación con el OI experimentador, como gustar, parecer, interesar, importar y ocurrir. Este papel semántico es también posible para el sujeto y esta cercanía al sujeto queda reflejada en que la concordancia es prácticamente obligatoria. Cuando este OI es explícito, suele ser preverbal, animado y determinado, mientras que el sujeto suele aparecer pospuesto e incluso llegar a tener forma de oración (no me gusta que fumes).

El segundo papel semántico más frecuente del OI bivalente es el beneficiario. Los verbos existenciales como pasar, quedar y faltar son los que más concuerdan con su objeto indirecto, en forma explícita o implícita. El verbo dar, a su vez, forma las frases hechas como me da la gana, me da la impresión o no me da tiempo.

1 Las tablas en este apartado siempre representan los diez verbos más frecuentes de cada grupo, si el número no es menor. 
Tabla 14

\begin{tabular}{|l|c|c|c|c|c|c|}
\hline & implícito & $\%$ & + concord. & $\%$ & - concord. & $\%$ \\
\hline gustar & 943 & $77,4 \%$ & 273 & $22,4 \%$ & 3 & $0,2 \%$ \\
\hline parecer & 287 & $84,9 \%$ & 51 & $15,1 \%$ & 0 & $0 \%$ \\
\hline pasar & 150 & $70,1 \%$ & 64 & $29,9 \%$ & 0 & $0 \%$ \\
\hline interesar & 130 & $77,8 \%$ & 28 & $16,8 \%$ & 9 & $5,4 \%$ \\
\hline dar & 121 & $76,6 \%$ & 24 & $15,2 \%$ & 13 & $8,2 \%$ \\
\hline importar & 112 & $73,2 \%$ & 40 & $26,1 \%$ & 1 & $0,7 \%$ \\
\hline ocurrir & 100 & $70,9 \%$ & 41 & $29,1 \%$ & 0 & $0 \%$ \\
\hline hablar & 99 & $70,7 \%$ & 19 & $13,6 \%$ & 22 & $15,7 \%$ \\
\hline quedar & 90 & $84,1 \%$ & 17 & $15,9 \%$ & 0 & $0 \%$ \\
\hline faltar & 81 & $81,8 \%$ & 17 & $17,2 \%$ & 1 & $1 \%$ \\
\hline
\end{tabular}

Las construcciones ditransitivas o trivalentes (Tabla 15) son las más típicas para el objeto indirecto, que ocupa aquí el papel de receptor, meta o beneficiario. Las más frecuentes son las construcciones verbales donde el OI ocupa el papel de receptor del mensaje. El mensaje, es decir, el OD, suele tener la forma de oración y el OI suele estar implícito. Los más frecuentes son los verbos de comunicación decir, contar, pedir y preguntar.

Un grupo importante de OI trivalentes está formado por los verbos de apoyo dar (I) (me da miedo, le dio una vuelta, darle las gracias) y hacer (no le hace caso, me hace falta, hacerle un favor). Otro grupo lo forman verbos ditransitivos típicos como dar (II) y ofrecer, con un OI receptor. Los dos grupos de verbos son muy heterogéneos en cuanto a la forma del OI.

Tabla 15

\begin{tabular}{|l|c|c|c|c|c|c|}
\hline & implícito & $\%$ & + concord. & $\%$ & - concord. & $\%$ \\
\hline dar I & 563 & $62,6 \%$ & 114 & $12,7 \%$ & 222 & $24,7 \%$ \\
\hline decir & 519 & $86,9 \%$ & 64 & $10,7 \%$ & 14 & $2,3 \%$ \\
\hline hacer & 362 & $74,5 \%$ & 70 & $14,4 \%$ & 54 & $11,1 \%$ \\
\hline contar & 270 & $87,7 \%$ & 34 & $11 \%$ & 4 & $1,3 \%$ \\
\hline dar II & 244 & $82,7 \%$ & 38 & $12,9 \%$ & 13 & $4,4 \%$ \\
\hline pedir & 188 & $69,1 \%$ & 27 & $9,9 \%$ & 57 & $21 \%$ \\
\hline preguntar & 166 & $75,5 \%$ & 36 & $16,4 \%$ & 18 & $8,2 \%$ \\
\hline permitir & 109 & $85,2 \%$ & 6 & $4,7 \%$ & 13 & $10,2 \%$ \\
\hline ofrecer & 77 & $64,7 \%$ & 9 & $7,6 \%$ & 33 & $27,7 \%$ \\
\hline explicar & 91 & $81,3 \%$ & 11 & $9,8 \%$ & 10 & $8,9 \%$ \\
\hline
\end{tabular}

En la Tabla 16 vemos la distribución de las formas del objeto directo según la valencia sintáctica:

1. OD monovalente (solo OD): Hace calor.

2. OD bivalente (SUJ + OD): Busco una secretaria.

3. OD trivalente (SUJ + OI + OD): Le han dado un golpe. 
Tabla 16

\begin{tabular}{|l|c|c|c|c|c|c|}
\hline & implícito & $\%$ & + concord. & $\%$ & - concord. & $\%$ \\
\hline OD 1valente & 14 & $1,5 \%$ & 0 & $0 \%$ & 951 & $98,5 \%$ \\
\hline OD 2valente & 9.474 & $18,2 \%$ & 637 & $1,2 \%$ & 42.031 & $80,6 \%$ \\
\hline OD 3valente & 738 & $10,5 \%$ & 55 & $0,8 \%$ & 6.235 & $88,7 \%$ \\
\hline
\end{tabular}

De los casos de objeto directo monovalente, una mitad pertenece al verbo haber y la segunda mitad, al verbo hacer (Tabla 17). Este objeto aparece casi siempre en la forma explícita no concordada, lo cual es lógico. El verbo haber exige un objeto pospuesto, indeterminado o no determinado, sin preposición, mencionado por primera vez en el discurso - un foco prototípico. El verbo hacer se comporta de la misma manera en las construcciones vinculadas al tiempo en los dos sentidos básicos de la palabra (hace dos horas, hace sol). Este hacer monovalente exige un objeto postverbal, inanimado, no determinado y forma con él frases hechas, lo que implica que este objeto no puede estar concordado ni implícito.

Tabla 17

\begin{tabular}{|l|c|c|c|c|c|c|}
\hline & implícito & $\%$ & + concord. & $\%$ & - concord. & $\%$ \\
\hline haber & 16 & $2,7 \%$ & 0 & $0 \%$ & 579 & $97,3 \%$ \\
\hline hacer & 0 & $0 \%$ & 0 & $0 \%$ & 599 & $100 \%$ \\
\hline
\end{tabular}

El objeto directo más típico es el que junto con el sujeto forma construcciones transitivas. Este OD bivalente concuerda con el verbo con más frecuencia que los demás OD. Aunque se trata de un grupo sintáctica y semánticamente muy heterogéneo, podemos ver en la Tabla 18 que el papel más frecuente de este OD es el "objeto de interés" de los verbos de percepción y cognición (saber, ver, mirar). Es natural que los verbos mentales sean tan frecuentes en el habla, ya que ésta siempre tiene carácter antropocéntrico y egocéntrico. Sin embargo, la distribución de las formas es tan variada que no se puede generalizar. Los verbos con el porcentaje más alto del OD implícito, ver y mirar, concuerdan también con más frecuencia que el resto; la forma reduplicada aparece en más de $2 \%$ de los casos. La explicación es que este objeto suele ser animado y determinado.

Por el contrario, los verbos creer, pensar y decir suelen exigir un objeto directo en forma de oración, así que casi no concuerdan con él. Tampoco los verbos tener, querer y dar, los cuales además tienen el porcentaje más bajo de OD implícito. El verbo querer en el sentido de desear normalmente exige un infinitivo, forma que nunca concuerda. Los verbos tener y dar suelen formar frases hechas con su objeto: dar una vuelta, dar clases, dar un paseo; tener razón, tener 18 años, tener tiempo, tener miedo, tener suerte, tener ganas. Estos objetos tienen forma fija, no llevan preposición y en la mayoría de los casos no aparece artículo. 
Tabla 18

\begin{tabular}{|l|c|c|c|c|c|c|}
\hline & implícito & $\%$ & + concord. & $\%$ & - concord. & $\%$ \\
\hline tener & 125 & $2,6 \%$ & 40 & $0,8 \%$ & 4.601 & $96,5 \%$ \\
\hline hacer & 530 & $20,2 \%$ & 52 & $2 \%$ & 2.042 & $77,8 \%$ \\
\hline saber & 361 & $14,9 \%$ & 24 & $1 \%$ & 2.033 & $84,1 \%$ \\
\hline ver & 668 & $30 \%$ & 57 & $2,6 \%$ & 1.500 & $67,4 \%$ \\
\hline creer & 125 & $7,7 \%$ & 11 & $0,7 \%$ & 1.495 & $91,7 \%$ \\
\hline querer & 16 & $1,7 \%$ & 0 & $0 \%$ & 921 & $98,3 \%$ \\
\hline dar & 26 & $3,1 \%$ & 11 & $1,3 \%$ & 790 & $95,5 \%$ \\
\hline mirar & 405 & $49 \%$ & 19 & $2,3 \%$ & 402 & $48,7 \%$ \\
\hline pensar & 83 & $10,3 \%$ & 5 & $0,6 \%$ & 715 & $89 \%$ \\
\hline decir & 82 & $10,4 \%$ & 7 & $0,9 \%$ & 696 & $88,5 \%$ \\
\hline
\end{tabular}

El objeto directo trivalente (Tabla 19) concuerda menos con el verbo que el OD bivalente y también aparece menos en la forma implícita. El rol semántico más importante del OD trivalente es el mensaje de un proceso verbal. Los verbos de comunicación como decir, contar, pedir y preguntar normalmente exigen un OD en forma de oración, así que la concordancia con estos objetos es muy rara. Sin embargo, la forma implícita es muy común.

El segundo grupo más grande lo representan los verbos dar (I) y hacer que forman parte de frases hechas como darle miedo, darle razón, darle vuelta, darle importancia, hacerle caso, hacerle daño, hacerle falta. Ya comentamos que este tipo de objeto no puede concordar ni aparece en forma implícita.

Un tercer grupo importante lo forman los verbos como dar (II) y ofrecer, que son unos verbos ditransitivos prototípicos. Su objeto directo suele ser un paciente inanimado sin preposición, pero puede aparecer implícito.

Tabla 19

\begin{tabular}{|l|c|c|c|c|c|c|}
\hline & implícito & $\%$ & + concord. & $\%$ & - concord. & $\%$ \\
\hline dar I & 19 & $2,1 \%$ & 2 & $0,2 \%$ & 874 & $97,7 \%$ \\
\hline decir & 107 & $17,9 \%$ & 4 & $0,7 \%$ & 486 & $81,4 \%$ \\
\hline hacer & 9 & $1,9 \%$ & 7 & $1,4 \%$ & 470 & $96,7 \%$ \\
\hline contar & 71 & $23,1 \%$ & 3 & $1 \%$ & 234 & $76 \%$ \\
\hline dar II & 57 & $19,6 \%$ & 3 & $1 \%$ & 230 & $79 \%$ \\
\hline pedir & 38 & $14 \%$ & 0 & $0 \%$ & 234 & $86 \%$ \\
\hline preguntar & 24 & $10,9 \%$ & 1 & $0,5 \%$ & 195 & $88,6 \%$ \\
\hline permitir & 2 & $1,6 \%$ & 0 & $0 \%$ & 126 & $98,4 \%$ \\
\hline ofrecer & 12 & $10,1 \%$ & 0 & $0 \%$ & 107 & $89,9 \%$ \\
\hline explicar & 19 & $17 \%$ & 5 & $4,5 \%$ & 88 & $78,6 \%$ \\
\hline
\end{tabular}




\subsection{Estructura del enunciado}

Siguiendo la tradición checa (Zavadil y Čermák 2010), distinguimos dos estructuras funcionales del enunciado:

1. La estructura comunicativa tiene carácter interno. Divide el enunciado entre tema y rema. El primer miembro del enunciado suele ser el tema, que es el punto de partida, el asunto del que se va a hablar. El resto del enunciado, el rema, es precisamente lo que se dice sobre el tema.

2. La estructura informativa es de carácter externo. Es equivalente a la categoría llamada topicalidad. El tópico representa información dada, mientras que el foco representa información nueva, acentuada. El tópico suele corresponder al tema del enunciado y el foco, al rema.

El tópico incluye todo lo conocido del contexto, en el sentido más amplio de la palabra. O se trata de un referente ya mencionado en el discurso, o de algo/alguien conocido por los participantes del acto comunicativo, o de algo/alguien presente en el acto comunicativo. El tópico lleva un peso fonético mínimo (nunca lleva énfasis entonativo) y un peso morfológico mínimo (puede estar implícito o en forma de palabras anafóricas y deícticas). El foco, por su parte, incluye todo lo nuevo, inesperado o contrastivo. Es la parte del enunciado más enfatizada, típicamente en forma de palabra plena u oración.

En este artículo he decidido tratar las dos estructuras en un solo apartado, ya que se encuentran muy entrelazadas. El objeto en español, como en muchas otras lenguas, suele ocupar la posición postverbal, remática, la que corresponde al foco del enunciado. Cuando está en la posición marcada, preverbal, hablamos de una tematización del objeto. "La tematicidad implica topicalidad y es también una característica del sujeto; por lo que la duplicación marca la proximidad semántico-pragmática del CDIR con el sujeto y, al mismo tiempo, contribuye a distinguirlo de él" (García-Miguel y Vázquez Rozas 1994). A veces, en cambio, el objeto se tematiza para destacar su carácter focal, está enfatizado, y en este caso nunca concuerda. El objeto así focalizado normalmente aparece en las exclamativas o tiene sentido contrastivo. Así que distinguimos tres combinaciones posibles:

1. objeto - rema - foco: Ayer he visto a Juan.

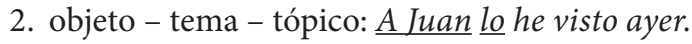

3. objeto - tema - foco: A Juan he visto ayer, no a José.

La base de datos nos permite investigar solamente la estructura comunicativa: distingue la posición preverbal (temática) y postverbal (remática) del objeto. Como el único rasgo claramente distintivo de la estructura informativa es la entonación, no se puede investigar en un corpus, y mucho menos en la parte de la lengua escrita. 
Tabla 20

\begin{tabular}{|l|c|c|c|c|c|c|c|c|}
\hline \multirow{2}{*}{} & \multicolumn{4}{|c|}{ OI } & \multicolumn{4}{c|}{ OD } \\
\cline { 2 - 9 } & + con. & $\%$ & - con. & $\%$ & + con. & $\%$ & - con. & $\%$ \\
\hline preverbal & 547 & $95,1 \%$ & 28 & $4,9 \%$ & 490 & $46,5 \%$ & 564 & $53,5 \%$ \\
\hline postverbal & 913 & $38,2 \%$ & 1.475 & $61,8 \%$ & 397 & $0,8 \%$ & 50.256 & $99,2 \%$ \\
\hline
\end{tabular}

La tabla 20 deja bien claro que el objeto indirecto preverbal aparece casi siempre concordado, mientras que el objeto directo postverbal no concuerda casi nunca. Así que vemos que la estructura del enunciado tiene mucha repercusión en la concordancia del verbo con el objeto. Entre los OI antepuestos no concordados, además de los OI obviamente focalizados, hay varios casos de dislocación (el OI está separado del resto por coma), lo cual constituye una variante extrema de tematización, que libera al objeto de la estructura sintáctica. Para un análisis complejo de la estructura temática en español véase Jiménez Juliá (1996). Entre los OD pospuestos concordados, un tercio lo forman los pronombres personales y otro tercio, las formas del cuantificador todo. Los dos grupos se caracterizan por una concordancia regular.

\subsection{Canal}

La reduplicación siempre se ha encontrado más extendida en la lengua oral que en la lengua escrita. En la mayoría de las variantes del español, el uso de la concordancia del verbo con el OD pospuesto es considerado muy coloquial y la gente más culta tiende a evitarla. En la lengua escrita, que es menos espontánea y tiende a seguir la norma, la concordancia con el objeto aparece aun menos.

Hasta este momento hemos investigado solamente el español escrito; en este apartado vamos a compararlo con el español hablado. En la Tabla 21 vemos que la diferencia es muy relevante. En el habla espontánea aparece mucha dislocación, lo que produce concordancia.

Tabla 21

\begin{tabular}{|l|c|c|c|c|c|c|c|c|}
\hline \multirow{2}{*}{} & \multicolumn{4}{|c|}{ OI } & \multicolumn{4}{c|}{ OD } \\
\cline { 2 - 9 } & + con. & $\%$ & - con. & $\%$ & + con. & $\%$ & - con. & $\%$ \\
\hline lengua escrita & 1.531 & $49 \%$ & 1.593 & $51 \%$ & 908 & $1,6 \%$ & 56.313 & $98,4 \%$ \\
\hline lengua hablada & 591 & $84,4 \%$ & 109 & $15,6 \%$ & 447 & $4,2 \%$ & 10.097 & $95,8 \%$ \\
\hline
\end{tabular}

\subsection{Registro social y regional}

Ahora trataremos de explicar brevemente las posibles causas por las que en algunas variantes del español el uso de la concordancia del objeto difiere de las demás variantes. Todos los datos proceden de Fernández-Ordóñez (1999).

En cuanto al leísmo y el laísmo, no se ha demostrado ninguna influencia en la concordancia en el dialecto de Madrid, donde están presentes los dos fenómenos. Sin embargo, en el español del País Vasco, el leísmo está generalizado con los OD animados de género 
masculino y femenino. La causa podemos encontrarla en la influencia del euskera, que carece de la categoría de género. Este leísmo "vasco" influye en la concordancia del OD. Pero, sobre todo, el verbo vasco concuerda regularmente con agente, paciente y beneficiente, lo que influye con certeza en la concordancia más frecuente en el español del País Vasco. Mientras que los OD animados concuerdan incluso en la posición postverbal, los OD inanimados, curiosamente, no concuerdan en algunos contextos en que la concordancia suele ser regular, incluso en algunos casos de OD implícito (Me agarró el collar y me $\underline{\emptyset}$ rompió.). Este fenómeno -la ausencia tanto del objeto explícito como del clítico- se llama objeto nulo y con certeza procede del euskera.

La influencia del euskera en el leísmo, en la concordancia del verbo con el objeto y en el fenómeno de objeto nulo en el español parece más cierta si miramos otras dos variantes del español, el español andino y el quiteño. Ambas están en contacto con el quechua, lengua no indoeuropea que tiene mucho en común con el euskera. El quiteño, dialecto de la capital ecuatoriana, se caracteriza por un leísmo generalizado (Le contrataré al taxi.). La distinción de caso y de género ha desaparecido por completo, así que los únicos clíticos de objeto para la tercera persona son le y les. La concordancia con el OD pospuesto es más frecuente, pero, como en el dialecto del País Vasco, la concordancia falta en los contextos donde la esperaríamos, como es el objeto antepuesto o implícito (Le $\underline{\varnothing}$ vamos a entregar ahora.). Con exagerar un poco, podríamos afirmar que en el quiteño todo está al revés.

El español andino, hablado en las zonas montañosas de Perú y Bolivia, guarda bastante parecido con el quiteño. A diferencia del dialecto ecuatoriano, en esta variante se distingue el caso, mientras que no se distingue el género y tampoco el número. Así que para el objeto directo de tercera persona solo existe un clítico lo, y para el objeto indirecto, le. La concordancia con el OD pospuesto es casi regular, incluso con los OD inanimados e indeterminados (Lo veía las armas.). Al contrario, puede faltar con los OD en posición temática (A la chica he visto en misa.).

Las variantes del español mexicano que están en contacto con el náhuatl y con las lenguas mayas, se caracterizan por una concordancia con el OD pospuesto generalizada. Algunos dialectos en Paraguay y noroeste de Argentina que están en contacto con el guaraní, no distinguen ni número ni género ni caso, así que el único clítico de objeto es el dativo le. Otra anomalía en estas zonas es la posible aparición de un pronombre personal tónico no concordado.

Partiendo de lo que acabamos de resumir, se podría suponer que la diferencia entre la variante española y la americana sería mayor en el caso de la concordancia del objeto directo pospuesto. La Tabla 22 muestra la diferencia entre la lengua escrita de España y la de América. La concordancia con el OI es más frecuente en América, lo que corresponde a la afirmación de Belloro (2007) de que en muchas variantes americanas está generalizada la concordancia con el OI receptor. Hemos visto que en algunos dialectos americanos la concordancia con el OD pospuesto es muy común. Sorprendentemente, según nuestro corpus, la concordancia con el OD es más frecuente en España. 
Tabla 22

\begin{tabular}{|l|c|c|c|c|c|c|c|c|}
\hline \multirow{2}{*}{} & \multicolumn{4}{|c|}{ OI } & \multicolumn{4}{c|}{ OD } \\
\cline { 2 - 9 } & + con. & $\%$ & - con. & $\%$ & + con. & $\%$ & - con. & $\%$ \\
\hline España & 1.196 & $46,2 \%$ & 1.391 & $53,8 \%$ & 765 & $1,7 \%$ & 44.739 & $98,3 \%$ \\
\hline América & 335 & $62,4 \%$ & 202 & $37,6 \%$ & 143 & $1,2 \%$ & 11.574 & $98,8 \%$ \\
\hline
\end{tabular}

La Tabla 23 compara la frecuencia de la concordancia en los tres subcorpus hablados de nuestro corpus. No es posible investigar por separado el habla de Madrid y la de Sevilla, así que otra vez tenemos España frente a América. En el dialecto argentino es un poco más frecuente la concordancia, sobre todo con el objeto indirecto. Es evidente que en este campo queda todavía mucho por investigar. La lucha entre la norma y el uso es bastante imprevisible y a veces, sorprendente.

Tabla 23

\begin{tabular}{|l|c|c|c|c|c|c|c|c|}
\hline & \multicolumn{4}{|c|}{ OI } & \multicolumn{4}{c|}{ OD } \\
\cline { 2 - 9 } & + con. & $\%$ & - con. & $\%$ & + con. & $\%$ & - con. & $\%$ \\
\hline Madrid + Sevilla & 453 & $81,7 \%$ & 101 & $18,3 \%$ & 335 & $4,2 \%$ & 7.588 & $95,8 \%$ \\
\hline Buenos Aires & 138 & $94,5 \%$ & 8 & $5,5 \%$ & 112 & $4,3 \%$ & 2.509 & $95,7 \%$ \\
\hline
\end{tabular}

\section{El concepto de accesibilidad}

Es evidente que hay tantos factores que influyen en la concordancia del verbo con el objeto que es imposible elegir uno principal. Sin embargo, hemos elegido tres factores primarios, lo cual corresponde a la siguiente afirmación de García-Miguel:

En el caso de la concordancia con el objeto, parece claro que las posibilidades de "duplicación” están condicionadas por rasgos inherentes de los participantes, como la animación y la determinación, y sobre todo por factores informativos. Los dos primeros aspectos están en la base de la obligatoriedad de la concordancia con los pronombres personales (tónicos) y también en su mayor frecuencia relativa con frases nominales de referente animado y/o definido. Los factores informativos se manifiestan en la concordancia con el CDIR tematizado no focalizado y en la correlación entre duplicación de CIND e información conocida. En conjunto, la concordancia con los objetos es más factible en aquellos casos en que éstos guardan mayores semejanzas con el sujeto, siguiendo una tendencia análoga (ya que no idéntica) a la que rige el uso de la preposición $a$. (García-Miguel 1991)

Como vemos, todos los demás factores siempre los podemos “descomponer" en estos tres factores primarios - la animación, la determinación y la estructura informativa o topicalidad. Este último término implica, a diferencia del anterior, una categoría gradual. Se trata de una escala entre un referente conocido o previsto, y otro no conocido o sorprendente. Los tres factores representan las propiedades típicas del sujeto, el actante más central, así que es natural que el objeto que tenga más de estas propiedades tienda más a concordar. Aparte de estos tres factores internos, queda el registro, que es un factor externo. 
Los tres factores primarios podemos unirlos bajo el concepto de accesibilidad, aplicado a la concordancia del objeto por Belloro (2007) y por Vázquez Rozas y García Salido (2012). La accesibilidad es una categoría gradual que distingue la medida en la que un referente es identificable por el interlocutor. El referente más accesible es el que ha aparecido en un contexto inmediato o está presente en el mismo acto comunicativo. El referente menos accesible es algo nuevo o sorprendente, algo que el interlocutor no tiene en la mente.

Parece que la accesibilidad influye tanto en la determinación como en la topicalidad del objeto. Podríamos afirmar que es el correlato pragmático de las dos categorías, aunque en el caso de la determinación, es solo uno de los valores posibles de esta categoría, como hemos visto en el apartado respectivo. Y como las entidades animadas suelen ser los tópicos del habla, podríamos decir que la animacidad, por su parte, influye en la accesibilidad.

La accesibilidad está estrechamente relacionada con la forma lingüística. La idea es que los elementos más accesibles suelen llevar menor carga fonética y semántica. Si la aplicamos al objeto, resulta que el referente que está en el centro de la atención del interlocutor, tendrá la forma de clítico, es decir, forma implícita. El referente que no se puede identificar de ninguna manera del contexto, que se encuentra inaccesible al interlocutor, tendrá la forma explícita no concordada. Y el referente que sigue presente pero ya no está en el centro de la atención del interlocutor, tendrá la forma explícita concordada: el clítico es signo de la relativa accesibilidad del referente y la forma léxica sirve para recordar algo que no está tan accesible.

Según Belloro (2007), la forma no marcada del objeto indirecto es el clítico (la forma implícita), mientras que en el caso del objeto directo es la forma explícita no concordada. Así, al OI lo llama topical argument y al OD, focal argument. Vázquez Rozas y García Salido (2012) afirman que el OI es en general un actante más accesible que el OD y que la forma de clítico es tan típica para el OI (como también, por ejemplo, para los pronombres personales) que se ha gramaticalizado como signo de concordancia.

\section{Conclusión}

Los rasgos prototípicos del sujeto -su carácter animado, determinado y topical-, equivalen a los factores principales que determinan la concordancia del verbo con el objeto. El objeto que posea más de estas propiedades del sujeto, tenderá más a concordar. El objeto indirecto se acerca bastante al sujeto en muchos aspectos, incluso lo supera en algunos (animación, forma implícita). Con esta razón se puede explicar que su concordancia es más frecuente que la del objeto directo, típicamente inanimado y focal.

De estos factores primarios se derivan los factores secundarios, como la clase de palabras, el papel semántico o la estructura comunicativa. Así, por ejemplo, la concordancia de los pronombres personales, inherentemente animados y determinados, está completamente gramaticalizada. La concordancia del objeto indirecto como experimentador, que es un papel semántico posible también para el sujeto, es casi regular, dado que es normalmente animado, determinado y topical. Un objeto en posición temática concuer- 
da con mucha mayor frecuencia que un objeto pospuesto, ya que el tema del enunciado habitualmente equivale al tópico.

El concepto de accesibilidad une a los tres factores primarios bajo un principio único y así proporciona una interpretación bastante compleja de las distintas formas del objeto. La forma depende del grado en que el referente es accesible para el oyente. Si el referente está activo en su conciencia, suele tener forma implícita. A su vez, la forma explícita concordada se emplea cuando es necesario hacer el referente más accesible para el oyente, recordarle o mencionar por primera vez una cosa que, sin embargo, le es conocida. Y por último, si el referente es totalmente desconocido para el oyente o es introducido en un contexto inesperado, por lo que no está activo en su conciencia, se hace necesario expresarlo mediante una forma explícita no concordada.

La concordancia es más frecuente con un objeto expresado habitualmente en forma implícita. El 75\% de todos los OI tienen forma de clítico, comparado con solo el $20 \%$ de los OD. En el español escrito actual, la mitad de todos los OI explícitos concuerdan, mientras que en el caso de los OD, la concordancia no alcanza el dos por ciento.

En algunas variantes sudamericanas la reduplicación parece ser regular: tanto la del objeto indirecto como la del directo. Se trata de la lengua hablada por gente menos culta, sobre todo en la zona andina, donde el español está en contacto con las lenguas indígenas. Estas lenguas se caracterizan sobre todo por la carencia de la categoría de género, lo que lleva a los hablantes bilingües a simplificar radicalmente el paradigma de los clíticos españoles de tercera persona. Estos cambios están relacionados con un aumento notable de la concordancia, que a menudo alcanza la regularidad. Sería muy interesante investigar con más detalle la naturaleza de la influencia de las lenguas indígenas en la concordancia del objeto en español.

De una manera parecida aumenta la concordancia en el dialecto del País Vasco, influido por el euskera. El leísmo de la variante madrileña, al contrario, parece que no afecta notablemente la concordancia, aunque la concordancia en esta zona es más corriente de lo que dice la norma. De todas maneras se puede ver un aumento general de la concordancia en la lengua oral en comparación con la escrita. Este hecho lo consideramos una muestra del desarrollo continuo del fenómeno.

Se podría predecir que con el tiempo, la concordancia del OI con el predicado alcanzará la regularidad propia del sujeto. Por el contrario, la frecuencia de la concordancia del OD no cambia diacrónicamente. Los clíticos de objeto son un ejemplo del fenómeno de la variación sincrónica, que Company (2002) define como la coexistencia de formas en distintas fases de gramaticalización. Esta variación impide una interpretación sencilla del fenómeno de la concordancia del verbo con el objeto.

\section{BIBLIOGRAFÍA}

Ariza, M. (2013): La preposición A de objeto: Teorias y panorama. Lexis, 13.2, pp. 203-222.

Barrenechea, A. M. - Orecchia, T. (1979): La duplicación de objetos directos e indirectos en el español hablado en Buenos Aires. In: A. M. Barrenechea (ed.), Estudios lingüísticos y dialectológicos: temas hispánicos. Buenos Aires: Hachette, pp. 73-101. 
Belloro, V. A. (2007): Spanish Clitic Doubling: a Study of the Syntax-Pragmatic Interface. Buffalo. $\mathrm{PhD}$ dissertation, State University of New York at Buffalo. [online]. [cit. 2012-03-17]. Accesible en: $<\mathrm{http}$ ///linguistics.buffalo.edu/people/faculty/vanvalin/rrg/Belloro-Spanish_Clitic_Doubling .pdf $>$.

Company Company, C. (2002): Reanálisis en cadena y gramaticalización: Dativos problemáticos en la historia del español. Verba, 29, pp. 31-69.

Fernández-Ordóñez, I. (1999): Leísmo, laísmo y loísmo. In: I. Bosque - V. Demonte (eds.) Gramática descriptiva de la lengua española. Madrid: Espasa Calpe, vol. I, pp. 1317-1397.

Fernández Soriano, O. (1993): Los pronombres átonos. Madrid: Taurus.

García-Miguel, J. M. (1991): La duplicación de complemento directo e indirecto como concordancia. Verba, 18, pp. 375-410.

García-Miguel, J. M. - Vázquez Rozas, V. (1994): Lingüística de corpus y lingüística descriptiva: el caso de la duplicación de objetos. Boletín de la Sociedad Española para el Procesamiento del Lenguaje Natural, 14, pp. 47-62. [online]. [cit. 2012-03-17]. Accesible en: <http://www.sepln.org/revistaSEPLN /revista/14/14-Pag47.pdf>.

Jiménez Juliá, T. (1996): Eje temático y tema en español. In: M. Casado Velarde (ed.), Scripta philologica in memoriam Manuel Taboada Cid. Servicio de Publicaciones Universidade da Coruña, pp. 453-492.

Vázquez Rozas, V. (1995): El complemento indirecto en español. Santiago de Compostela: USC.

Vázquez Rozas, V. - García Salido, M. (2012): A discourse-based analysis of object clitic doubling in Spanish. In: K. Davidse - T. Breban - L. Brems - T. Mortelmans (eds.), Grammaticalization and Language Change: New Reflections. Amsterdam: John Benjamins, pp. 269-296.

Zavadil, B. - Čermák, P. (2010): Mluvnice současné španělštiny: lingvisticky interpretační př́stup. Praha: Karolinum.

\section{Base de datos}

http://adesse.uvigo.es

\section{Kateřina Ziková}

Instituto de Estudios Románicos, Facultad de Filosofía y Letras, Universidad Carolina

nám. Jana Palacha 2, 11638 Praha 1

kacaz@way.cz 